\title{
Diabetes and breast cancer risk: a meta-analysis
}

\author{
P Boyle', M Boniol',', A Koechlin', C Robertson',2, F Valentini', K Coppens', L-L Fairley', M Boniol', T Zheng ${ }^{3}$, \\ Y Zhang ${ }^{3}$, M Pasterk', M Smans', MP Curado', P Mullie', S Gandini ',4, M Bota', GB Bolli ${ }^{5}$, J Rosenstock ${ }^{6}$ and \\ P Autier'
}

IInternational Prevention Research Institute, 95 cours Lafayette, 69006 Lyon, France; ${ }^{2}$ Department of Mathematics and Statistics, University of Strathclyde, Livingstone Tower, 26 Richmond Street, Glasgow GI IXH, Scotland; ${ }^{3}$ Yale University School of Public Health, 60 College Street, P.O. Box 208034, New Haven, CT 06520-8034, USA; ${ }^{4}$ European Institute of Oncology, Via Ripamonti 435, 20146 Milano, Italy; ${ }^{5}$ Department of Internal Medicine and Oncology, S.M. della Misericordia Hospital, University of Perugia, 06132 Perugia, Italy; ${ }^{6}$ Dallas Diabetes and Endocrine Center at Medical City, 7777 Forest Lane C-685, Dallas, TX 75230, USA

BACKGROUND: The potential of an increased risk of breast cancer in women with diabetes has been the subject of a great deal of recent research.

METHODS: A meta-analysis was undertaken using a random effects model to investigate the association between diabetes and breast cancer risk.

RESULTS: Thirty-nine independent risk estimates were available from observational epidemiological studies. The summary relative risk (SRR) for breast cancer in women with diabetes was 1.27 (95\% confidence interval (Cl), I. I6-I.39) with no evidence of publication bias. Prospective studies showed a lower risk (SRR I.23 (95\% Cl, I.I2-1.35)) than retrospective studies (SRR I.36 (95\% Cl, I.I3I.63)). Type I diabetes, or diabetes in pre-menopausal women, were not associated with risk of breast cancer (SRR I.00 (95\% Cl, 0.74-I.35) and SRR 0.86 (95\% Cl, 0.66-I.I2), respectively). Studies adjusting for body mass index (BMI) showed lower estimates (SRR I.I6 (95\% Cl, I.08-1.24)) as compared with those studies that were not adjusted for BMI (SRR I.33 (95\% Cl, I.I8-1.5।)). CONCLUSION: The risk of breast cancer in women with type 2 diabetes is increased by $27 \%$, a figure that decreased to $16 \%$ after adjustment for BMI. No increased risk was seen for women at pre-menopausal ages or with type I diabetes.

British Journal of Cancer (2012) I 07, 1608-1617. doi:I0.1038/bjc.2012.4I4 www.bjcancer.com

Published online 20 September 2012

(C) 2012 Cancer Research UK

Keywords: diabetes; breast cancer; meta-analysis; body mass index

Diabetes is one of the commonest chronic conditions in men and women. In 2010, it was estimated that there were approximately 285 million patients with diabetes, aged $20-79$ years, around the world; this represents a prevalence of $6.4 \%$ (Sicree et al, 2006). Complications from diabetes, such as coronary artery and peripheral vascular disease, stroke, diabetic neuropathy, amputations, renal failure and blindness are resulting in increasing disability, reduced life expectancy and enormous health costs for virtually every society. Diabetes and its complications contribute to a substantial proportion of causes of death in high-resource countries, and in many lower-resource regions, diabetes is rapidly increasing in incidence and prevalence. It is estimated that the global burden of diabetes will reach 439 million people (prevalence of $7.7 \%$ ) by 2030 (Sicree et al, 2006).

Cancer is increasingly a global problem (Boyle, 2006), and breast cancer is not only the commonest incident form of cancer in women worldwide but is the first or second most common in all regions of the world, and is responsible for approximately 1.4 million new cases annually (Boyle and Levin, 2008). The incidence of breast cancer is increasing almost everywhere throughout the world, for example in Asia (Shin et al, 2010), although the mortality from breast cancer is declining in many high-income

*Correspondence: Dr M Boniol; E-mail: mathieu.bonio|@i-pri.org Received 15 May 2012; revised 10 August 2012; accepted 20 August 2012; published online 20 September 2012 countries (Autier et al, 2010). Notable exceptions to this increasing trend in incidence have taken place in the United States where there has been a sharp decrease in incidence from 2002-2003 that occurred in women 50-69 years old, who predominantly, but not exclusively, had oestrogen receptor positive tumours and may reflect the early benefit of the reduced use of hormone replacement therapy (Jemal et al, 2007).

The global burden of breast cancer doubled between 1975 and 2000. It seems certain to double again between now and 2030, and the great majority of this burden will fall on the low-income and lower middle-income countries where the resources to deal with the current situation, never mind the future increases, are absent to a great degree (Boyle and Howell, 2010). Focus on breast cancer up until now has almost entirely been on top of the situation in high-income countries. With growth and ageing of the world's population, notable increases in life expectancy in many countries and the sharp tendency towards adoption of a westernised lifestyle with lower fertility rates, cancer is a rapidly growing global problem (Boyle, 2006) and not one which the majority of the world is ready to cope with.

Initially hypothesised by Freund (1885), women with breast cancer have been described as having higher rates of diabetes than healthy women (Glicksman and Rawson, 1956). The potential of an increased risk of breast cancer in women with diabetes has been the subject of a great deal of recent research. Given how common both breast cancer and diabetes are in our ageing societies, this is an important issue for public health. 
Past meta-analysis have analysed the association between diabetes and breast cancer risk reported by observational studies (Wolf et al, 2005; Larsson et al, 2007; Liao et al, 2011), but it included a maximum of only 20 studies, which limited their statistical power and capacity to perform heterogeneity analysis.

The objective of the present study is to summarise results from observational studies on the association between breast cancer and diabetes, and to investigate source of heterogeneity in the estimated risks.

\section{MATERIALS AND METHODS}

\section{Literature search, eligibility and data abstraction}

A systematic literature search and quantitative analysis was conducted based on a protocol developed for this study, and is reported following the MOOSE guidelines regarding meta-analysis of observational studies (Stroup et al, 2000). Published reports in peer-reviewed journals were obtained from the following databases using validated search strategies: Ovid MEDLINE database, ISI Web of Science, Science Citation Index Expanded and PUBMED (http://www.ncbi.nlm.nih.gov/entrez/query.fcgi). We used combinations of the following keywords and corresponding MeSH terms for the literature searches: 'Diabetes Mellitus', 'breast neoplasms', 'breast cancer'. Other sources were found in the reference lists of the retrieved articles and preceding reviews, including metaanalysis, on the topic. The literature search was conducted up to October 2011.

Studies eligible for this review had to meet the following criteria: (i) report data on incident invasive cases of breast cancer or on breast cancer deaths; (ii) report on whether women included in studies had diabetes or not; and (iii) have a cross-sectional, casecontrol, cohort, nested case-control design or a randomised trial including a control group of women in which the exposure of interest had been assessed in the same way as in breast cancer women. Control women had to have no history of breast cancer or of known benign breast tumour disease. For cohort studies, the control group could be external, like a cancer registry or a cause of death registry. Ecological studies, case reports, reviews and editorials were not considered eligible.

The search was restricted to articles published in English language. There was no restriction on geographical location of studies. We screened titles and looked at abstracts when the title suggested a study possibly meeting the main criteria. If the abstract content was relevant, full copies of articles were retrieved and fully read by at least two co-authors. Articles reporting on prognosis after breast cancer diagnosis were excluded. Review articles not reporting original data were also excluded, but checked for references.

A standard data extraction form was used for abstracting data from eligible publications. This data extraction was conducted by two co-authors, and when necessary, a third co-author analysed discrepancies. We extracted any measure of association of the risk of breast cancer associated with diabetes, taking the most adjusted risk. We did not differentiate between odds ratios, relative risks and standardised incidence ratios, and we considered that each was an estimate of relative risk, later referred as RR. We also extracted the $95 \%$ confidence interval $(95 \% \mathrm{CI})$ around the RR.

Note that two studies (de Waard and Baanders-van Halewijn, 1974; O'Mara et al, 1985) did not calculate any measure of dispersion (95\% CI, variance, etc.) for their RR. For these articles, variances were taken as the average variance of all other studies. In addition, the standardised incidence ratio (SIR) reported by Wideroff et al (1997) has only one decimal and a very narrow CI, being presented as SIR $=1.1$ (95\% CI, 1.1-1.2). To improve the variance estimate, which could be underestimated by using these original values, the CI was re-estimated based on the variance of the crude rate and the point estimate and $95 \%$ CI compatible with the rounding performed in the original article. The SIR included in our analysis was therefore 1.14 (95\% CI, 1.06-1.22).

We also extracted the type of study separating prospective studies from others (mainly case-control studies) and the various adjustment factors used. We extracted whether the study was restricted to type 1 diabetes, type 2 diabetes, or included both types of diabetes and when the type of diabetes was not reported. We attempted to identify studies whose primary objective was the investigation of the association between diabetes and breast cancer. However, in most articles, the diabetes-breast cancer association was just one of the many exposure-breast cancer relationships that were explored. We therefore examined whether the diabetes has been self-declared or obtained from medical records or prescription databases, because studies recording diabetes from medical records or prescription database probably had a greater focus on diabetes than studies with diabetes as an item in a questionnaire.

When data were available, stratified by menopausal status, specific RR and 95\% CI were gathered. In a heterogeneity analysis, we additionally extracted RR adjusted and not adjusted for body mass index (BMI), and both RRs were provided by a study.

\section{Statistical analysis}

The various estimates of RR and their CIs were transformed into $\log (\mathrm{RR})$ and the corresponding variance was calculated. Where no estimates were reported, the crude estimates and 95\% CI were calculated from tabular data. From the transformed data, maximum likelihood summary relative risks (SRR) were calculated using a random effects model including two sources of variation (between study variance and, when applicable, within study variance; van Houwelingen et al, 2002). The meta-analysis was carried out in programming language $\mathrm{R}$ (version 2.13.1, GNU General Public Licence, 2011) and package metafor (Viechtbauer, 2010). Heterogeneity across studies was evaluated by $I^{2}$, which represents the percentage of total variation across studies that is attributable to heterogeneity rather than to chance (Higgins and Thompson, 2002). Sensitivity analyses were carried out to evaluate the influence of each study on the overall estimate from the metaanalysis.

Statistically significant results are more likely to be easily and quickly published in international peer-reviewed journals. Null or

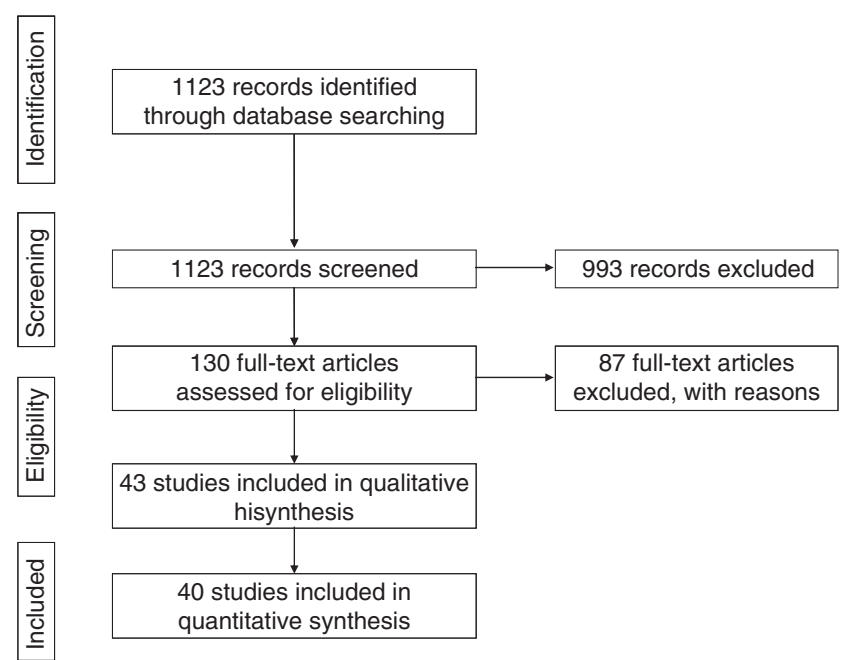

Figure I Flow chart of the literature search strategy to identify observational studies on breast cancer risk and diabetes. 
Table I Main characteristics of studies included in the meta-analysis, ranked by year of publication

\begin{tabular}{|c|c|c|c|c|c|c|c|}
\hline \multirow[b]{2}{*}{ First author (year) } & \multirow[b]{2}{*}{ Country } & \multirow[b]{2}{*}{$\begin{array}{l}\text { Study } \\
\text { design }\end{array}$} & \multicolumn{3}{|c|}{ Number of cases } & \multirow[b]{2}{*}{$\begin{array}{l}\text { Follow-up (years) } \\
\text { in cohorts }\end{array}$} & \multirow[b]{2}{*}{$\begin{array}{l}\text { Age } \\
\text { groups }\end{array}$} \\
\hline & & & All women & Pre-menopause & Post-menopause & & \\
\hline Li et al $(20 \mid \mathrm{I})$ & USA & CS & 7830 & NR & NR & - & 18-99 \\
\hline Lambe et al (20। I) & Sweden & CS & 5967 & 1425 & 4272 & - & $>25$ \\
\hline Rosato et al (20II) & Italy & $\mathrm{CC}$ & 3869 & NR & 3869 & - & $33-80$ \\
\hline Hemminki et al (20।0) & Sweden & $\mathrm{CH}$ & 844 & NR & NR & 15 & $>39$ \\
\hline Sanderson et al (20|0) & USA & $\mathrm{CC}$ & 190 & NR & NR & - & $30-79$ \\
\hline Jordan et al (2009) & Thailand & $\mathrm{CC}$ & 43 & NR & NR & - & NR \\
\hline Tseng et al (2009) & Taiwan & $\mathrm{CH}$ & 482 & NR & NR & 10 & $>25$ \\
\hline Rollison et al (2008) & USA & $\mathrm{CC}$ & 2324 & 871 & 1448 & - & Mean age 55.5 \\
\hline Beji and Reis (2007) & Turkey & $\mathrm{CC}$ & 405 & $N R$ & NR & - & $28-72$ \\
\hline Garmendia et al (2007) & Chile & $\mathrm{CC}$ & 170 & NR & 122 & - & $33-86$ \\
\hline Wu et al (2007) & USA & $\mathrm{CC}$ & 1224 & 547 & 677 & - & $25-74$ \\
\hline Inoue et al (2006) & Japan & $\mathrm{CH}$ & 451 & NR & NR & 10.7 & $40-69$ \\
\hline Khan et al (2006) & Japan & $\mathrm{CH}$ & 120 & NR & NR & 8 & $40-79$ \\
\hline Lipscombe et al (2006) & Canada & $\mathrm{CH}$ & 6107 & NR & 6107 & 4.5 & $55-79$ \\
\hline Jee et al (2005) & Korea & $\mathrm{CH}$ & $289^{a}$ & NR & NR & $10(\max )$ & 30-95 \\
\hline Rapp et al (2006) & Austria & $\mathrm{CH}$ & 50 & NR & NR & 8.6 & $35-54$ \\
\hline Swerdlow et al (2005) & UK & $\mathrm{CH}$ & 75 cases / 27 deaths & NR & NR & 18 & $<49$ \\
\hline Coughlin et al (2004) & USA & $\mathrm{CH}$ & 4346 & NR & $N R$ & $16(\max )$ & $>30$ \\
\hline Lawlor et al (2004) & UK & CS & 147 & NR & NR & - & $60-79$ \\
\hline Resta et al (2004) & Italy & $\mathrm{CC}$ & 1663 & NR & NR & - & $24-85$ \\
\hline Michels et al (2003) & USA & $\mathrm{CH}$ & 5605 & 1469 & 3562 & $22(\max )$ & $30-55$ \\
\hline Verlato et al (2003) & Italy & $\mathrm{CH}$ & 57 & NR & NR & $10(\max )$ & Mean age 69.2 \\
\hline Zendehdel et al (2003) & Sweden & $\mathrm{CH}$ & 69 & 69 & NR & 14.4 & $0-30$ \\
\hline Sinagra et al (2002) & Italy & CC & 50 & NR & NR & - & Mean age 49.4 \\
\hline Mink et al (2002) & USA & $\mathrm{CH}$ & 187 & NR & NR & 7.1 & 45-64 \\
\hline Baron et al (200l) & USA & $\mathrm{CC}$ & 5564 & NR & NR & - & $50-75$ \\
\hline Weiss et al (1999) & USA & $\mathrm{CC}$ & 2158 & NR & $N R$ & - & $20-54$ \\
\hline Goodman et al (1997) & Japan & $\mathrm{CH}$ & 161 & NR & NR & 8.31 & All ages \\
\hline Hjalgrim et al (1997) & Denmark & $\mathrm{CH}$ & | | & NR & NR & 12.9 & All ages \\
\hline Weiderpass et al (1997) & Sweden & $\mathrm{CH}$ & $1 \mid 45$ & NR & NR & 6.7 & Mean age 64.2 \\
\hline Wideroff et al (1997) & Denmark & $\mathrm{CH}$ & 777 & NR & NR & 5.7 & All ages \\
\hline Steenland et al (1995) & USA & $\mathrm{CH}$ & 163 & NR & NR & 7.7 & $25-74$ \\
\hline Sellers et al (1994) & USA & $\mathrm{CH}$ & 611 & NR & 611 & $5(\max )$ & $55-69$ \\
\hline Moseson et al (1993) & USA & $\mathrm{CC}$ & 354 & 90 & 264 & - & $22-86$ \\
\hline Adami et al (1991) & Sweden & $\mathrm{CH}$ & 240 & NR & NR & 5.2 & All ages \\
\hline O'Mara et al (1985) & USA & $\mathrm{CC}$ & 1883 & NR & $N R$ & - & $30-89$ \\
\hline Ragozzino et al (1982) & USA & $\mathrm{CH}$ & 14 & NR & $N R$ & 8.6 & All ages \\
\hline Adami and Rimsten (1978) & Sweden & $\mathrm{CC}$ & 179 & 30 & 149 & - & Mean age 63 \\
\hline Muck et al (1975) & Germany & $\mathrm{CC}$ & 217 & NR & NR & - & All ages \\
\hline $\begin{array}{l}\text { de Waard and Baanders-van } \\
\text { Halewijn }(1974)^{b}\end{array}$ & The Netherlands & $\mathrm{CH}$ & 70 & NR & 70 & 5.4 & $55-75$ \\
\hline
\end{tabular}

Abbreviations: $\mathrm{CC}=$ case-control; $\mathrm{CH}=$ cohort; $\mathrm{CS}=$ cross-sectional; NCC = nested case-control in a cohort; NR= not reported. The control group consisted in a 5 I I highrisk group of women receiving a diagnostic mammogram either due to inconclusive or abnormal results, and in 468 low-risk group of women with no family history of BC, no history of breast biopsy and negative mammograms for the past 2 years. ${ }^{2}$ Not reported but computed from incidence rate and sample size in Table 5 from Jee et al (2005).

${ }^{b}$ Did not report confidence intervals. Variance was taken as the average variance of all other studies.

non-significant results are harder to publish. This has to be taken into account in meta-analyses, because this may introduce publication bias. Publication bias was graphically assessed using a funnel-plot-based approach; the regression of log (OR) on the sample size, weighted by the inverse of the variance (Macaskill test) was calculated (Macaskill et al, 2001). To complete this visual analysis, the three main publication bias tests were computed, namely Begg's test (rank correlation test; Begg and Mazumdar, 1994), Egger's test (weighted linear regression test for funnel plot symmetry; Egger et al, 1997) and Macaskill's test (Macaskill et al, 2001).

As sensitivity analysis for assessing the relative weight of each study on the SRR, the meta-analysis was run again, systematically omitting each study (leave-one-out analysis).

To investigate sources of heterogeneity, separate analyses were performed for type 1 and type 2 diabetes, for pre-menopausal and post-menopausal women, for BMI-adjusted risk estimates $v s$ not BMI-adjusted risk estimates, for studies on breast cancer mortality $v s$ studies on incident cases, and for self-declared and medically reviewed diabetes. To test for differences between subgroups, we conducted a meta-regression in a random-effect model, with subgroup variable as a fixed parameter. An analysis was also conducted for cohort studies and case-control studies separately.

\section{RESULTS}

Figure 1 summarises the process of literature search of the present meta-analysis. Overall, 43 studies have been identified from the literature search. Three studies were excluded (Franceschi et al, 1990; La Vecchia et al, 1994; Talamini et al, 1997), because they were included in Rosato et al, 2011.

The meta-analysis included 40 independent risk estimates reported in 40 articles (Table 1). Of these, 18 were retrospective (15 case-control, 3 cross-sectional) studies and 22 were prospective 


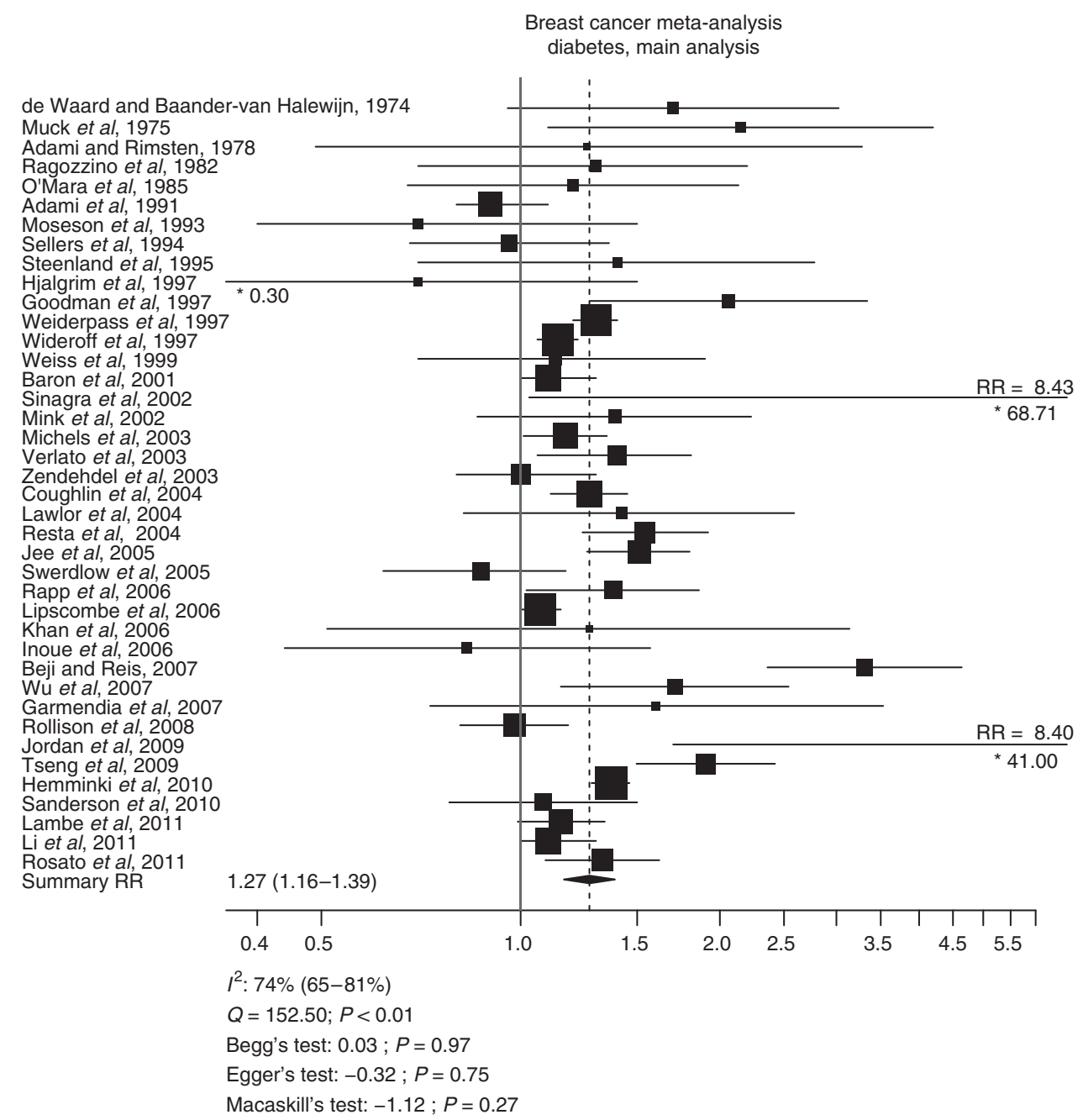

Figure 2 Forest plot of meta-analysis of breast cancer in women with diabetes. Individual studies represented by relative risk (RR) and $95 \%$ confidence interval $(\mathrm{Cl})$.

studies. Fifteen studies were conducted in Northern America, 1 in South America, 18 in Europe and 6 in Asia. Studies included a total of 56111 breast cancer cases. Study size ranged from 11 to 7830 breast cancer cases, with a median of 322 . The majority of cases (38560) were recruited in the northern American studies.

Figure 2 presents the meta-analysis of all 40 studies combined. The SRR of breast cancer in diabetic women was 1.27 (95\% CI, $1.16-1.39$ ) with $I^{2}=74 \%$ (95\% CI, 65-81\%), the percentage of heterogeneity which could not be explained by chance. The Begg's test $(0.03, P=0.97)$, the Egger's test $(-0.32, P=0.75)$ and the Macaskill's test $(-1.12, P=0.27)$ were non-significant, indicating that publication bias was unlikely.

The sensitivity analysis (leaving one out at a time) produced no statistically significantly increased or decreased summary odds ratio, although the findings from Beji and Reis (2007) were quite influential (Figure 3).

When the meta-analysis was restricted to the 22 prospective studies, the SRR was about the same as for all studies combined $(\mathrm{SRR}=1.23 \quad(95 \%$ CI, 1.12-1.35); Table 2), with substantial heterogeneity and no publication bias. Restricting the analysis to the 18 retrospective (mainly case-control) studies also leads to significantly elevated SRR that was higher than for cohort studies (SRR 1.36 (95\% CI, 1.13-1.63)) with similar heterogeneity and no publication bias. No significant difference was evidenced from meta-regression $(P=0.37)$.
A clear difference was identified according to whether studies adjusted or not for BMI; the SRR for BMI-adjusted studies was 1.16 (95\% CI, 1.08-1.24) with an $I^{2}$ of $11 \%$ (Figure 4 ), whereas in studies not adjusted for BMI, the SRR was 1.33 (95\% CI, 1.18-1.51) with an $I^{2}$ of $89 \%$ (Figure 5 ). These unadjusted studies contributed strongly to the heterogeneity, as the heterogeneity in adjusted studies was only $11 \%$. However, the adjusted and unadjusted SRRs were not significantly different in meta-regression $(P=0.34)$. The analysis restricted to studies that reported both RRs adjusted and not adjusted for BMI showed similar differences in SRRs (Table 2).

Four studies presented results for type 1 diabetes on its own. The SRR was 1 (95\% CI, $0.74-1.35)$ with an $I^{2}$ of $0 \%$ (i.e., no heterogeneity that could not be explained by chance alone) and no evidence of publication bias. On the contrary, women with type 2 diabetes had an increased risk of breast cancer (SRR 1.16 (95\% CI, 1.04-1.29)) based on 14 studies. The meta-regression did not show significant differences $(P=0.25)$. The majority of studies did not report the type of diabetes; in these 25 studies, the SRR was 1.37 (95\% CI, 1.20-1.56).

The SRR was different according to menopausal status. From the five original studies, which presented information about breast cancer diagnosed before the menopause, the SRR was 0.86 (95\% CI, $0.66-1.12$ ) with an $I^{2}$ of $0 \%$. In the 10 studies on breast cancer diagnosed after the menopause, the SRR was $1.15(95 \%$ CI, 1.07-1.24) with an $I^{2}$ of $47 \%$. The difference between pre-menopausal and post-menopausal women was statistically 


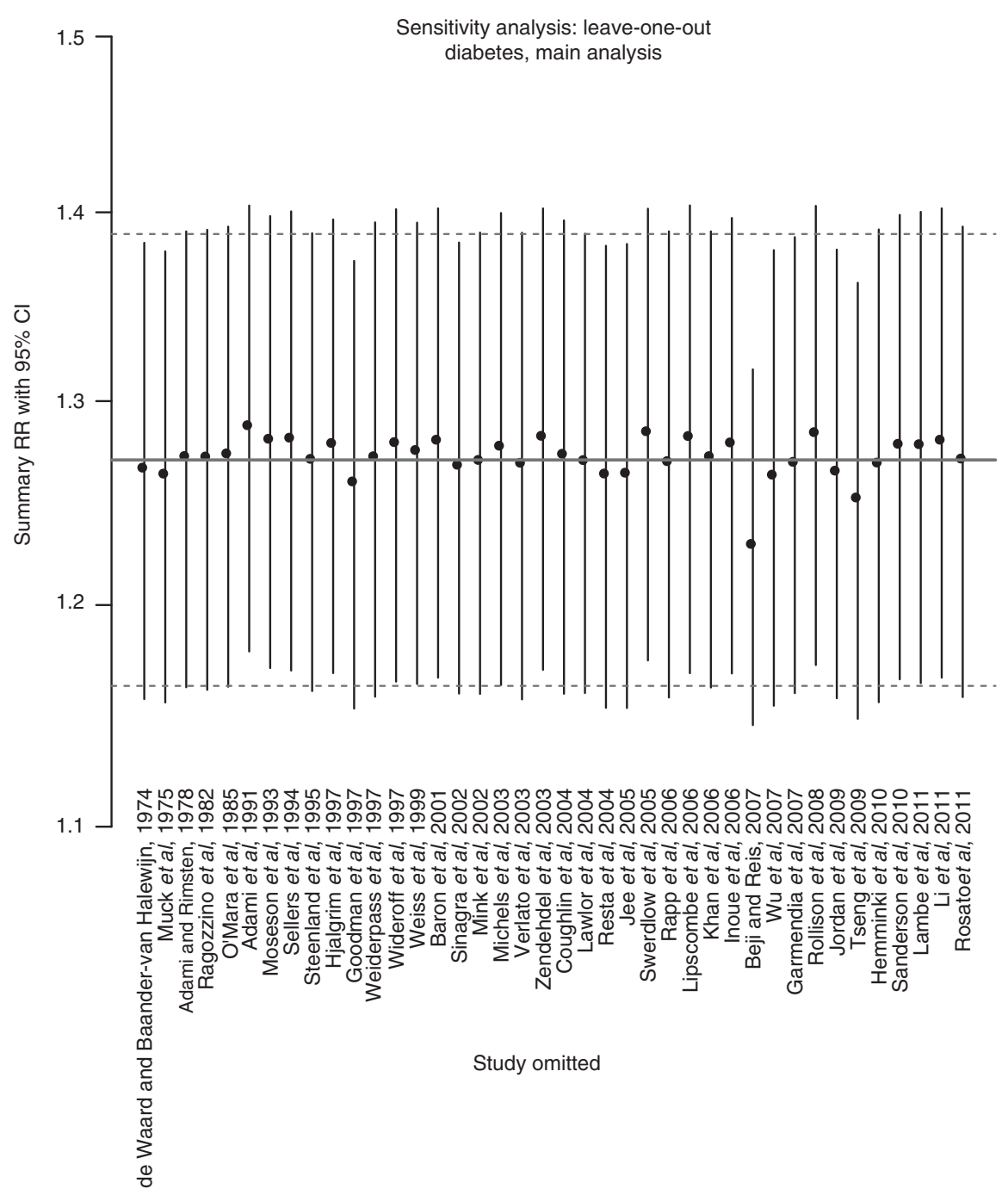

Figure 3 Sensitivity analysis (leave-one-out) of meta-analysis of risk of breast cancer women with diabetes.

significant in meta-regression $(P=0.004)$. The result in postmenopausal ages did not change significantly when restricted to studies on type 2 diabetes.

The stratified analysis on how the diabetes status was ascertained showed no difference between studies with selfdeclared diabetes or diabetes from medical records, the metaregression also showed no significant difference $(P=0.66)$.

Four studies (Verlato et al, 2003; Coughlin et al, 2004; Jee et al, 2005; Tseng et al, 2009) were conducted on breast cancer mortality, and the study of Swerdlow et al (2005) also reported risk for breast cancer mortality. When stratifying studies on mortality or incidence, considering the wide CI for mortality, we conclude that similar relationships with similar heterogeneity were found.

Figure 6 presents a cumulative meta-analysis, and it is apparent that the increased risk of breast cancer in women with diabetes was statistically significant in publications up until and including 1997, and has remained statistically elevated subsequently. The meta-regression did not find significant impact of publication year $(P=0.76)$.

\section{DISCUSSION}

For the 40 independent risk estimates combined, compared with women without a diagnosis of breast cancer, the risk of breast cancer in women was significantly associated with diabetes. Type 1 diabetes and diabetes in pre-menopausal women were not associated with significant increase risk of breast cancer. Adjustment for BMI in the original studies made an important difference in terms of risk with an higher risk in unadjusted studies $(\mathrm{SRR}=1.33)$ than in BMI-adjusted studies $(\mathrm{SRR}=1.16)$. Although this difference was not significant in meta-regression, the unadjusted studies had an important role in the heterogeneity, because unadjusted studies yielded highly variable and conflicting results. The findings were unchanged when the diagnosis of diabetes was self-reported or confirmed from review of medical records. When analysis was restricted to those studies where risk estimates of breast cancer could be obtained for post-menopausal women with type 2 diabetes, the risk of breast cancer was elevated (SRR 1.12 (95\% CI, 1.03-1.21)). The risk of breast cancer in studies with type not reported is slightly higher than the main analysis. This observation could be an artefact from inclusion of few studies adjusted on BMI (only five were adjusted) and several studies with retrospective design (12 studies). The risk did not substantially differ between studies on mortality and studies on incidental breast cancer. Of note is the Swerdlow et al (2005) study, which reported both outcomes had very close estimate: 0.86 for mortality and 0.87 for incidence. The largest study on diabetes and breast cancer mortality by Coughlin et al (2004) found an RR of 1.27, quite close to the summary estimate of the present meta-analysis. All these 
Table 2 Summary of results of meta-analyses of breast cancer and diabetes

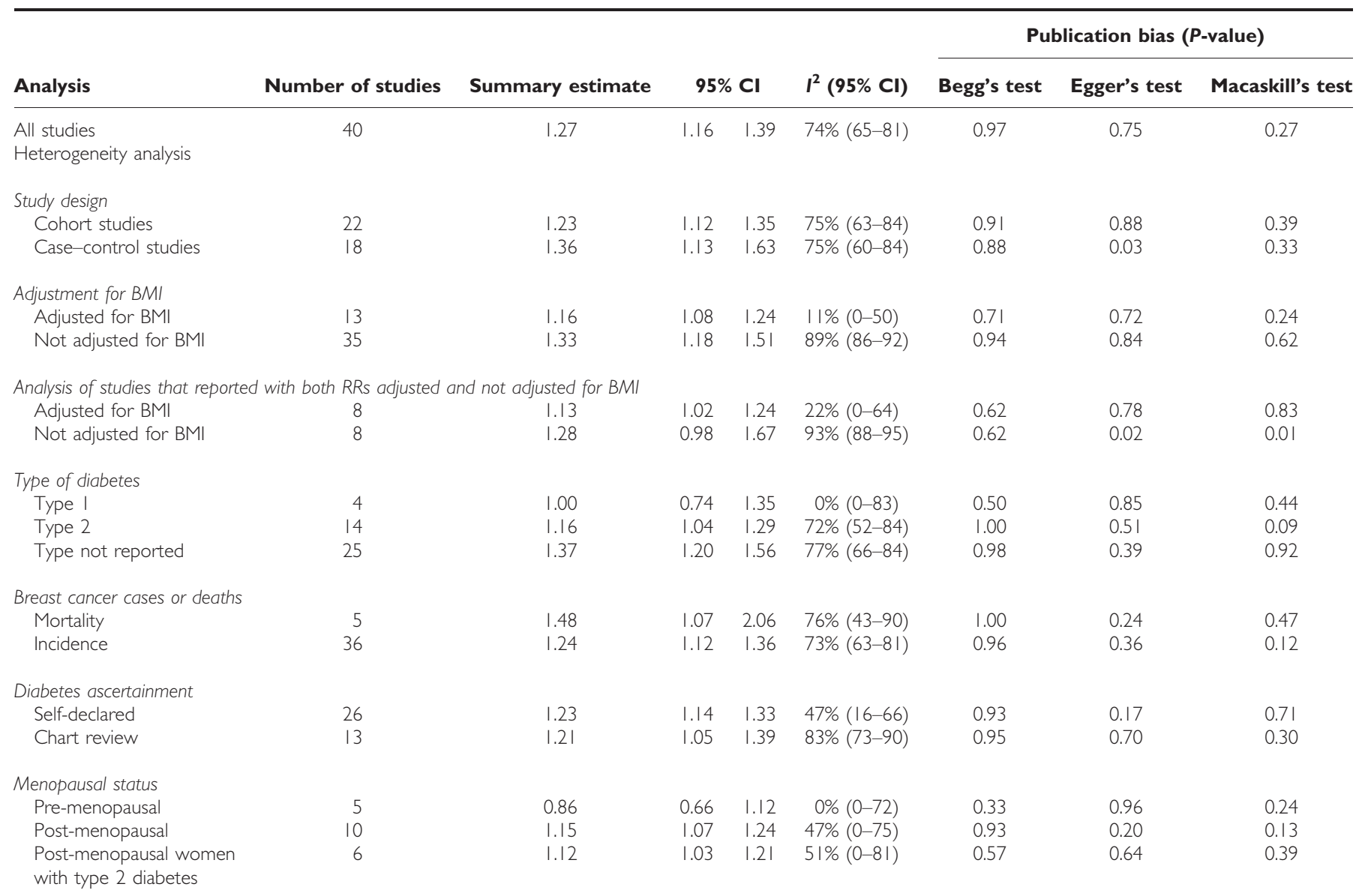

Abbreviations: $\mathrm{BMI}=$ body mass index; $\mathrm{Cl}=$ confidence interval; $\mathrm{RR}=$ relative risk.

elements suggest that the increase of breast cancer with diabetes is similar for both incidence and mortality. When meta-analysis was conducted on a temporal basis, the SRR became significant in 1997 and remained fairly constant (and statistically significantly increased), with addition of subsequent studies according to recency of publication.

The mechanisms by which type 2 diabetes might increase the risk of breast cancer are not known. Hyperinsulinaemia, a marker of insulin resistance in obesity and type 2 diabetes, has been advocated as potential factor (Plymate et al, 1990; Rosner, 1990; Singh et al, 1990; Kaaks, 1996). In addition, obesity is associated with type 2 diabetes and leads to a rise in endogenous oestrogen levels. Insulin inhibits the production of sex hormone-binding globulin (Barker et al, 1964; Van der Burg et al, 1988), which results in an increase in free steroid hormones, free oestrogens in particular, because testosterone successfully competes with oestrogen for the sex hormonebinding globulin (Conover et al, 1992). Hyperinsulinaemia may also have joint effects with the insulin growth factor I that could be involved in breast carcinogenic processes (Novosyadlyy et al, 2010).

In vitro insulin is also a growth-promoting hormone with mitogenic effects in both normal and malignant breast tissues (Lippman and Bolan, 1975; Cannata et al, 2010).

Another mechanism could be chronic hyperglycaemia that could increase the breast cancer risk, for instance, via the Warburg effect (Warburg, 1930; Brown and Simpson, 2010), that is, the mechanism by which cancer cells predominantly produce energy by a high rate of glycolysis in the cytosol rather than by glycolysis followed by the oxygen-dependent Krebbs cycle in mitochondria. But reviews of randomised trials showed no reduction in the risk of cancer with more intense glycaemic control of type 2 diabetes patients (Johnson and Bowker, 2011).

In summary, this meta-analysis found a significant increased risk of breast cancer among women with diabetes. The association between diabetes and breast cancer risk seemed to be restricted to post-menopausal women. The main factor influencing SRR is adiposity (as measured by the BMI). Studies that adjusted for BMI found lower SRRs than studies that did not adjust for this factor. The meta-regression analysis did not find that the difference in SRR between BMI-adjusted and non-adjusted studies was significant. However, because of considerable heterogeneity of results of studies that did not adjust, the meta-regression analysis is of limited power. Most studies adjusted for BMI by introducing the variable BMI as a continuous variable, which assumes a linear effect between BMI and breast cancer risk. However, there is no evidence that the assumption of a simple linear or a log-linear relationship between BMI and breast cancer risk is real, in particular when BMI is less than 25 (IARC, 2002).

It is also worth considering the hypothesis by which type 2 diabetes would be a marker of the adiposity-breast cancer association rather than being a genuine causation of this cancer. The risk of breast cancer is increased in obese post-menopausal 
Breast cancer meta-analysis

diabetes, heterogeneity, RR adjusted for BMI

Steenland et al, 1995

Weiss et al, 1999

Baron et al, 2001

Mink et al, 2002

Michels et al, 2003

Lawlor et al, 2004

Coughlin et al, 2004

Khan et al, 2006

Inoue et al, 2006

Rapp et al, 2006

Wu et al, 2007

Rollison et al, 2008

Li et al, 2011

Summary RR

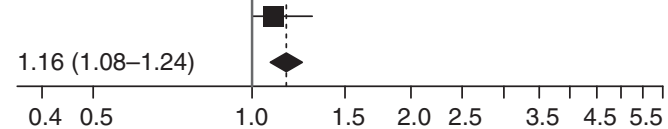

$I^{2}: 11 \%(0-50 \%)$

$Q=13.52 ; P=0.33$

Begg's test: $0.37 ; P=0.71$

Egger's test: $0.36 ; P=0.72$

Macaskill's test: $1.25 ; P=0.24$

Figure 4 Forest plot of meta-analysis of breast cancer and diabetes in studies with relative risk (RR) adjusted for BMI. Individual studies represented by $R R$ and $95 \%$ confidence interval $(\mathrm{Cl})$. women by around $50 \%$, whereas it is marginally reduced in premenopausal obese women (IARC, 2002). This risk pattern is similar to that obtained by our meta-analysis observed for diabetes and breast cancer. Hence, BMI could be acting like a classic confounder being related to both the exposure (diabetes) and the outcome (breast cancer).

\section{ACKNOWLEDGEMENTS}

Mathieu Boniol is the guarantor of the content. This study was part of works associated with an unrestricted research grant from Sanofi.

\section{Conflict of interest}

The authors declare no conflict of interest.

\section{Author Contributions}

$\mathrm{PB}$ contributed to discussion and wrote the manuscript; $\mathrm{MB}$ and $\mathrm{AK}$ researched data, conducted the statistical analysis, contributed to discussion and reviewed/edited the manuscript; CR, MP and SG contributed to discussion and reviewed/edited the manuscript; FV researched data and reviewed/edited manuscript; KC, Magali B, TZ and YZ researched data; L-LF, MS, MPC, PM and M Bota reviewed/ edited the manuscript; GB and JR contributed to discussion; PA researched data, contributed to discussion and reviewed/edited the manuscript.

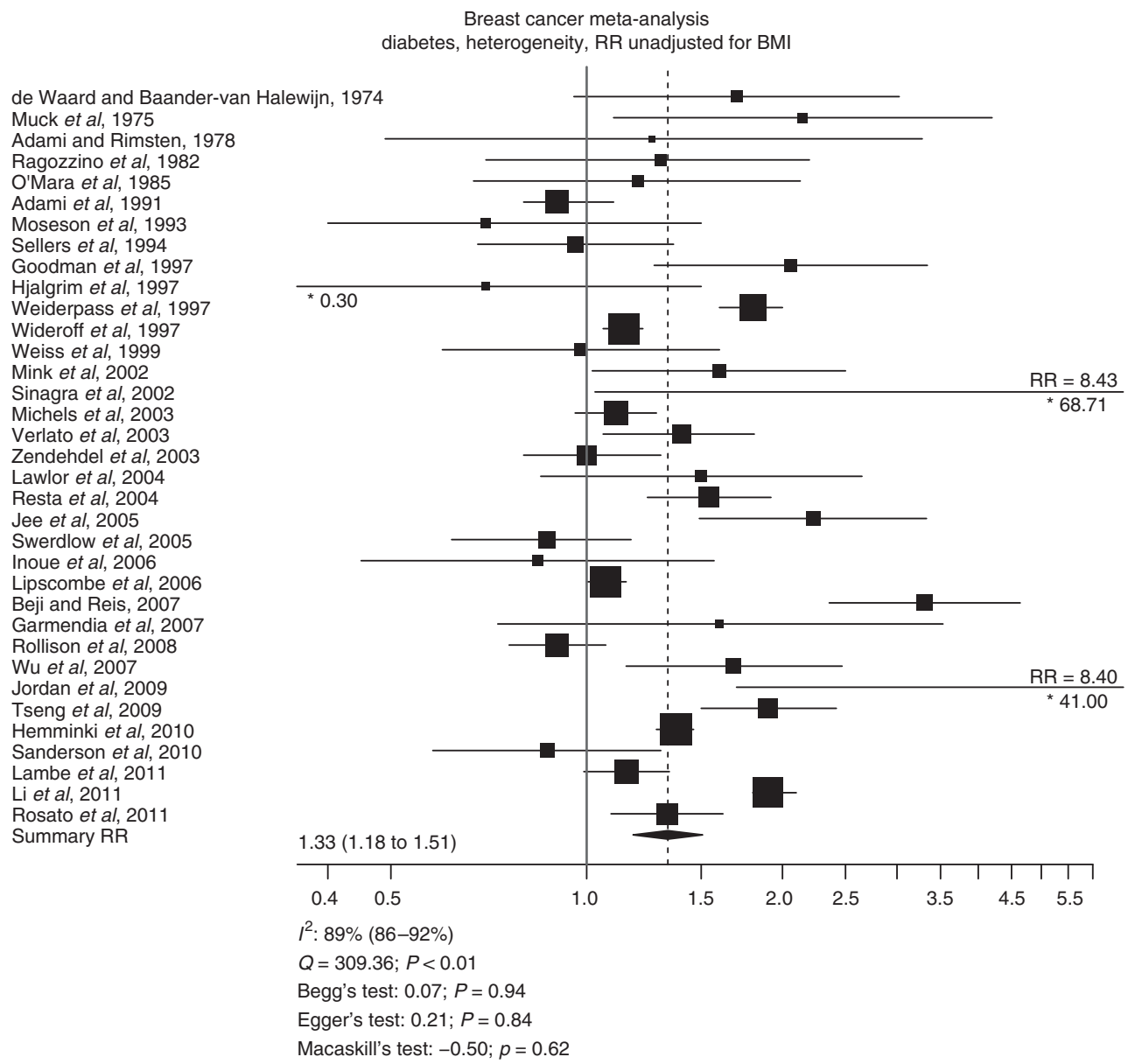

Figure 5 Forest plot of meta-analysis of breast cancer and diabetes in studies with relative risk (RR) not adjusted for BMI. Individual studies represented by $\mathrm{RR}$ and $95 \%$ confidence interval $(\mathrm{Cl})$. 
Breast cancer meta-analysis

diabetes, cumulative inclusion of studies

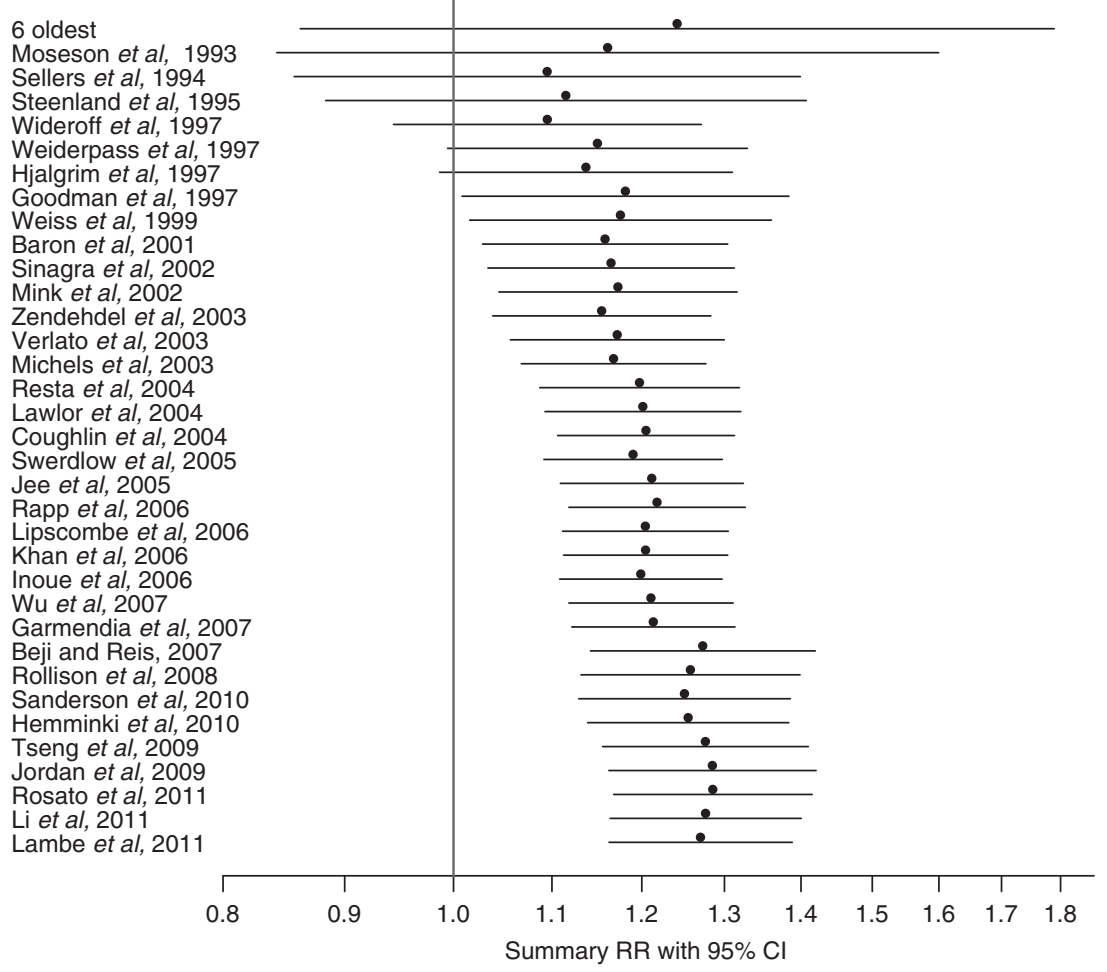

Figure 6 Cumulative temporal meta-analysis of breast cancer risk in diabetic women.

\section{REFERENCES}

Adami HO, McLaughlin J, Ekbom A, Berne C, Silvermand D, Hacker D, Persson I (1991) Cancer risk in patients with diabetes mellitus. Cancer Causes Control 2: 307-314

Adami HO, Rimsten A (1978) Prevalence of hypertension and diabetes in breast cancer: a case-control study in 179 patients and age-matched, non-hospitalized controls. Clin Oncol 4: 243-249

Autier P, Boniol M, La Vecchia C, Vatten L, Gavin A, Hery C, Heanue M (2010) Disparities in breast cancer mortality trends between 30 European countries: retrospective trend analysis of WHO mortality database. BMJ 341: c3620

Barker BE, Fanger H, Farnes P (1964) Human mammary slices in organ culture. I. Methods of culture and preliminary observations on the effects of insulin. Exp Cell Res 35: 437-448

Baron JA, Weiderpass E, Newcomb PA, Stampfer M, Titus-Ernstoff L, Egan KM, Greenberg ER (2001) Metabolic disorders and breast cancer risk (United States). Cancer Causes Control 12: 875-880

Begg CB, Mazumdar M (1994) Operating characteristics of a rank correlation test for publication bias. Biometrics 50: 1088-1101

Beji NK, Reis N (2007) Risk factors for breast cancer in Turkish women: a hospital-based case-control study. Eur J Cancer Care 16: $178-184$

Boyle P, Howell A (2010) The globalisation of breast cancer. Breast Cancer Res 12(Suppl 4): S7

Boyle P, Levin B (eds) (2008) World Cancer Report 2008. IARC: Lyon, France

Boyle P (2006) The Globalisation of cancer. Lancet 368: 629-630

Brown KA, Simpson ER (2010) Obesity and breast cancer: progress to understanding the relationship. Cancer Res 70: 4-7

Cannata D, Fierz Y, Vijayakumar A, Leroith D (2010) Type 2 diabetes and cancer: What is the connection? Mt Sinai J Med 77: 197-213

Conover CA, Lee PD, Kanaley JA, Clarkson JT, Jensen MD (1992) Insulin regulation of insulin-like growth factor binding protein- 1 in obese and non-obese humans. J Clin Endocrinol Metab 74: 1355-1360
Coughlin SS, Calle EE, Teras LR, Petrelli J, Thun MJ (2004) Diabetes mellitus as a predictor of cancer mortality in a large cohort of US adults. Am J Epidemiol 159: 1160-1167

de Waard F, Baanders-van Halewijn EA (1974) A prospective study in general practice on breast-cancer risk in postmenopausal women. Int $J$ Cancer 14: 153-160

Egger M, Smith GD, Phillips AN (1997) Meta-analysis: principles and procedures. BMJ 315: 1533-1537

Franceschi S, La Vecchia C, Negri E, Parazzini F, Boyle P (1990) Breast cancer risk and history of selected medical conditions linked with female hormones. Eur J Cancer 26: 781-785

Freund E (1885) Diagnosis des Carcinomas. Wien Med B1: 268-268

Garmendia ML, Pereira A, Alvarado ME, Atalah E (2007) Relation between insulin resistance and breast cancer among Chilean women. Ann Epidemiol 17: 403-409

Glicksman AS, Rawson RW (1956) Diabetes and altered carbohydrate metabolism in patients with cancer. Cancer 9: 1127-1134

Goodman MT, Cologne JB, Moriwaki H, Vaeth M, Mabuchi K (1997) Risk factors for primary breast cancer in Japan: 8-year follow-up of atomic bomb survivors. Prev Med 26: 144-153

Hemminki K, Li X, Sundquist J, Sundquist K (2010) Risk of cancer following hospitalisation for Type 2 diabetes. Oncologist 15: 548-555

Higgins JP, Thompson SG (2002) Quantifying heterogeneity in a metaanalysis. Stat Med 21: 1539-1558

Hjalgrim H, Frisch M, Ekbom A, Kyvik KO, Melbye M, Green A (1997) Cancer and diabetes - a follow-up study of two population-based cohorts of diabetic patients. J Intern Med 241: 471-475

Inoue M, Iwasaki M, Otani T, Sasazuki S, Noda M, Tsugane S (2006) Diabetes mellitus and the risk of cancer: results from a large-scale populationbased cohort study in Japan. Arch Intern Med 166: 1871-1877

International Agency for Research on Cancer (2002) IARC Handbooks of Cancer Prevention, Vol. 5, Weight Control and Physical Activity. IARC: Lyon, France 
Jee SH, Ohrr H, Sull JW, Yun JE, Ji M, Samet JM (2005) Fasting serum glucose level and cancer risk in Korean men and women. JAMA 293: $194-202$

Jemal A, Ward E, Thun MJ (2007) Recent trends in breast cancer incidence rates by age and tumour characteristics among United States women. Breast Cancer Res 9: R28

Johnson JA, Bowker SL (2011) Intensive glycaemic control and cancer risk in type 2 diabetes: a meta-analysis of major trials. Diabetologia 54: 25-31

Jordan S, Lim L, Vilainerun D, Banks E, Sripaiboonkij N, Seubsman SA, Sleigh A, Bain C (2009) Breast cancer in the Thai Cohort Study: an exploratory case-control analysis. Breast 18: 299-303

Kaaks R (1996) Nutrition, hormones, and breast cancer: is insulin the missing link? Cancer Causes Control 7: 605-625

Khan M, Mori M, Fujino Y, Shibata A, Sakauchi F, Washio M, Tamakoshi A (2006) Site-specific cancer risk due to diabetes mellitus history: evidence from the Japan Collaborative Cohort (JACC) Study. Asian Pac J Cancer Prev 7: 253-259

La Vecchia C, Negri E, Franceschi S, D'Avanzo B, Boyle P (1994) A case-control study of diabetes mellitus and cancer risk. $\mathrm{Br} J$ Cancer 70: $950-953$

Lambe M, Wigertz A, Gamo H, Walldius G, Jungner I, Hammar N (2011) Impaired glucose metabolism and diabetes and the risk of breast, endometrial and ovarian cancer. Cancer Causes Control 22: 1163-1171

Larsson SC, Mantzoros CS, Wolk A (2007) Diabetes mellitus and risk of breast cancer: a meta-analysis. Int J Cancer 121: 856-862

Lawlor DA, Davey Smith G, Ebrahim S (2004) Hyperinsulinaemia and increased risk of breast cancer: findings from the British Women's Heart and Health Study. Cancer Causes Control 15: 267-275

Li C, Balluz LS, Ford ES, Okoro CA, Tsai J, Zhao G (2011) Association between diagnosed diabetes and self-reported cancer among U.S. adults: findings from the 2009 Behavioural Risk Factors Surveillance System. Diabetes Care 34: 1365-1368

Liao S, Li J, Wei W, Wang L, Zhang Y, Li J, Wang C, Sun S (2011) Association between diabetes mellitus and breast cancer risk: a metaanalysis of the literature. Asian Pac J Cancer Prev 12: 1061-1065

Lippman ME, Bolan G (1975) Oestrogen responsive human breast cancer cells in long term tissue culture. Nature 256: 592-594

Lipscombe LL, Goodwin PJ, Zinman B, McLaughlin JR, Hux JE (2006) Diabetes mellitus and breast cancer: a retrospective population-based cohort study. Breast Cancer Res Treat 98: 349-356

Macaskill P, Walter SD, Irwig L (2001) A comparison of methods to detect publication bias in meta-analysis. Stat Med 20: 641-654

Michels KB, Solomon CG, Hu FB, Rosner BA, Hankinson SE, Colditz GA, Manson JE (2003) Type 2 diabetes and subsequent incidence of breast cancer in the Nurses' Health Study. Diabetes Care 26: 1752-1758

Mink PJ, Shahar E, Rosamond WD, Alberg AJ, Folsom AR (2002) Serum insulin and glucose levels and breast cancer incidence: the atherosclerosis risk in communities study. Am J Epidemiol 156: 349-352

Moseson M, Koenig KL, Shore RE, Pasternack BS (1993) The influence of medical conditions associated with hormones on the risk of breast cancer. Int J Epidemiol 22: 1000-1009

Muck BR, Trotnow S, Hommel G (1975) Cancer of the breast, diabetes and pathological glucose tolerance. Arch Gynäk 220: 73-81

Novosyadlyy R, Lann DE, Vijayakumar A, Rowzee A, Lazzarino DA, Fierz Y, Carboni JM, Gottardis MM, Pennisi PA, Molinolo AA, Kurshan N, Mejia W, Santopietro S, Yakar S, Wood TL, LeRoith D (2010) Insulinmediated acceleration of breast cancer development and progression in a nonobese model of type 2 diabetes. Cancer Res 70: 741-751

O'Mara BA, Byers T, Schoenfeld E (1985) Diabetes mellitus and cancer risk: a multisite case-control study. J Chronic Dis 38: 435-441

Plymate SR, Hoop RC, Jones RE, Matej LA (1990) Regulation of sex hormone-binding globulin production by growth factors. Metabolism 39: 967-970

Ragozzino M, Melton III LJ, Chu CP, Palumbo PJ (1982) Subsequent cancer risk in the incidence cohort of Rochester, Minnesota, residents with diabetes mellitus. J Chronic Dis 35: 13-19

Rapp K, Schroeder J, Klenk J, Ulmer H, Concin H, Diem G, Oberaigner W, Weiland SK (2006) Fasting blood glucose and cancer risk in a cohort of more than 140,000 adults in Austria. Diabetologia 49: 945-952

Resta F, Triggiani V, Sabbà C, Licchelli B, Ghiyasaldin S, Liso A, Schittulli F, Quaranta M, Paradiso A, Tafaro E, Guastamacchia E (2004) The impact of body mass index and type 2 diabetes on breast cancer: current therapeutic measures of prevention. Curr Drug Targets Immune Endocr Metab Disord 4: 327-333
Rollison DA, Giulano AR, Sellers TA, Laronga C, Sweeney C, Risendal B Baumgartner KB, Byers T, Slattery ML (2008) Population-based case-control study of diabetes and breast cancer risk in Hispanic and non-hispanic women living in US South-western States. Am J Epidemiol 167: 447-456

Rosato V, Bosetti C, Talamini R, Levi F, Montella M, Giacosa A, Negri E, La Vecchia C (2011) Metabolic syndrome and the risk of breast cancer in postmenopausal women. Ann Oncol 22: 2687-2692

Rosner W (1990) The functions of corticosteroid- binding globulin and sex-hormone-binding globulin: recent advances. Endocr Rev 11: 80-91

Sanderson M, Peltz G, Perez A, Johnson M, Vernon SW, Fernandez ME, Fadden MK (2010) Diabetes, physical activity and breast cancer among Hispanic women. Cancer Epidemiol 34: 556-561

Sellers TA, Sprafka JM, Gapstur SM, Rich SS, Potter JD, Ross JA, McGovern PG, Nelson CL, Folsom AR (1994) Does body fat distribution promote familial aggregation of adult onset diabetes mellitus and postmenopausal breast cancer? Epidemiology 5: 102-108

Shin HR, Joubert C, Boniol M, Hery C, Ahn SH, Won YJ, Nishino Y, Sobue T, Chen CJ, You SL, Mirasol-Lumague MR, Law SC, Mang O, Xiang YB, Chia KS, Rattanamongkolgul S, Chen JG, Curado MP, Autier P (2010) Recent trends and patterns in breast cancer incidence among Eastern and South-eastern Asian women. Cancer Causes Control 21: 1777-1785

Sicree R, Shaw J, Zimmet P (2006) Diabetes and impaired glucose tolerance. In Diabetes Atlas. 3rd ednGan D (ed)pp 15-109. International Diabetes Federation: Brussels, Belgium

Sinagra D, Amato C, Scarpitta AM, Brigandi M, Amato M, Saura G, Latteri MA, Caimi G (2002) Metabolic syndrome and breast cancer risk. Eur Rev Med Pharmacol Sci 6: 55-59

Singh A, Hamilton-Fairley D, Koistinen R, Seppala M, James VH, Franks S, Reed MJ (1990) Effect of insulin-like growth factor-type I (IGF-I) and insulin on the secretion of sex-hormone binding globulin and IGF-I binding protein (IBP-I) by human hepatoma cells. J Endocrinol 124: R1-R3

Steenland K, Nowlin S, Palu S (1995) Cancer incidence in the National Health and Nutrition Survey I. Follow-up data: diabetes, cholesterol, pulse and physical activity. Cancer Epidemiol Biomarkers Prev 4: 807-811

Stroup DF, Berlin JA, Morton SC, Olkin I, Williamson GD, Rennie D, Moher D, Becker BJ, Sipe TA, Thacker SB (2000) Meta-analysis of observational studies in epidemiology: a proposal for reporting. Meta-analysis Of Observational Studies in Epidemiology (MOOSE) group. JAMA 283: 2008-2012

Swerdlow AJ, Laing SP, Qiao Z, Slater SD, Burden AC, Botha JL, Waugh NR, Morris AD, Gatling W, Gale EA, Patterson CC, Keen H (2005) Cancer incidence and mortality in patients with insulin-treated diabetes: a UK cohort study. Br J Cancer 92: 2070-2075

Talamini R, Franceschi S, Favero A, Negri E, Parazzini F, La Vecchia C (1997) Selected medical conditions and risk of breast cancer. Br J Cancer 75: 1699-1703

Tseng CH, Chong CK, Tai TY (2009) Secular trend for mortality from breast cancer and the association between diabetes and breast cancer in Taiwan between 1995 and 2006. Diabetologia 52: 240-246

Van der Burg BB, Rutterman GR, Blankenstein MA, de Laat SW, van Zoelen EJJ (1988) Mitogenic stimulation of human breast cancer cells in a growth-defined medium: synergistic action of insulin and estrogen. J Cell Physiol 134: 101-108

van Houwelingen HC, Arends LR, Stijnen T (2002) Advanced methods in meta-analysis: multivariate approach and meta-regression. Stat Med 21 589-624

Verlato G, Zoppini G, Bonora E, Muggeo M (2003) Mortality from sitespecific malignancies in type 2 diabetic patients from Verona. Diabetes Care 26: 1047-1051

Viechtbauer W (2010) Conducting meta-analyses in $\mathrm{R}$ with the metafor package. J Stat Softw 36: 1-48

Warburg O (1930) The Metabolism of Tumors. Constable Press: London, United Kingdom

Weiderpass E, Gridley G, Persson I, Nyren O, Ekbom A, Adami HO (1997) Risk of endometrial and breast cancer in patients with diabetes mellitus. Int J Cancer 71: 360-363

Weiss HA, Brinton LA, Potischman NA, Brogan D, Coates RJ, Gammon MD, Malone KE, Schoenberg JB (1999) Breast cancer risk in young women and history of selected medical conditions. Int J Epidemiol 28: 816-823

Wideroff L, Gridley G, Mellemkjaer L, Chow WH, Linet M, Keehn S Borch-Johnsen K, Olsen JH (1997) Cancer incidence in a population based cohort of patients hospitalized with diabetes mellitus in Denmark. J Natl Cancer Inst 89: 1360-1365 
Wolf I, Sadetzki S, Catane R, Karasik A, Kaufman B (2005) Diabetes mellitus and breast cancer. Lancet Oncol 6: 103-111

Wu AH, Yu MC, Tseng C-C, Stanczyk FZ, Pike MC (2007) Diabetes and risk of breast cancer in Asian-American women. Carcinogenesis 28: 1561-1566
Zendehdel K, Nyren O, Ostenson CG, Adami HO, Ekbom A, Ye W (2003) Cancer incidence in patients with type 1 diabetes mellitus: a population- based cohort study in Sweden. J Natl Cancer Inst 95: $1797-1800$

This work is published under the standard license to publish agreement. After 12 months the work will become freely available and the license terms will switch to a Creative Commons Attribution-NonCommercial-Share Alike 3.0 Unported License. 